\title{
БЮДЖЕТНО-НАЛОГОВАЯ ПОЛИТИКА КНР В УСЛОВИЯХ ГЛОБАЛИЗАЦИИ МИРОВОЙ ЭКОНОМИКИ
}

\author{
(C) 2019 Чжан Ифэй \\ аспирант кафедры «Экономическая теория и менеджмент» \\ Московский педагогический государственный университет, Россия, Москва \\ E-mail: zd100606@yandex.ru
}

В данной статье анализируется политика Китайской Народной Республики в бюджетно-налоговой сфере. Анализируется динамика и структура доходов и расходов консолидированного бюджета Китая. Оценивается доля налоговых поступлений в структуре доходов консолидированного бюджета государства.

Ключевые слова: бюджет КНР, доходы бюджета, расходы бюджета, консолидированный бюджет Китая, налоговые поступления, неналоговые поступления

Введение. Китай на сегодняшний день является, ведущей экономикой мира оказывая существенное влияние на развитие мирохозяйственных связей в условиях глобализации. Это обуславливается эффективной внешнеторговой и внешнеэкономической политикой проводимой правительством государства в последние сорок лет.

Однако необходимо понимать, что внешнеэкономические достижения Китая во многом зависят от эффективности внутренней финансовой политики страны в целом и бюджетного планирования в частности. Стабильность государства в экономическом плане обусловлена эффективностью проведения внешнеторговых операций с одной стороны и грамотной внутренней бюджетной и налоговой политикой центрального и местного правительства с другой стороны. Финансовая политика государства позволяет стимулировать деловую активность и производственные процессы, а использование налоговых и неналоговых льгот в системе бизнеса позволяет качественно наращивать бизнес-процессы в различных отраслях народного хозяйства $[2,4]$.

Возвещенная внутренняя политика Китая в сфере бюджетных и налоговых отношений является возможностью использования данного опыта в системе индустриальных экономик для увеличения внутренней конкурентоспособности национального хозяйства, что и обуславливает актуальность темы данного научного исследования.

Изложение основного материала. Бюджетная система Китайской Народной Республи- ки весьма, своеобразна и в мировом контексте практически не имеет близких аналогов. Несмотря на то, что отдельным ее параметрам можно найти соответствия в бюджетных системах других стран, сочетание всех их одновременно практически беспрецедентно и на первый взгляд кажется парадоксальной комбинацией взаимопротиворечащих элементов [1, 3].

В рамках более, предметного раскрытия темы данной научной статьи проанализируем доходы и расходы консолидированного бюджета Китайской Народной Республики за период с 2014 года по 2017 год соответственно, а также на прогнозный период до 2023 года.

Для чего воспользуемся нижеприведенной диаграммой (Рисунок 1), на которой наглядно отображена динамика данных показателей за исследуемый период времени.

Как можно увидеть из вышеприведенной диаграммы произошли следующие изменения в системе поступлений и расходований средств государственного бюджета Китайской Народной Республики за период с 2014 по 2023 год:

- согласно прогнозным данным доходы бюджета вырастут на 152\% или 21,3 трлн. юаней с 14 трлн. юаней в 2014 году до показателя 35,3 трлн. долларов по итогам 2023 года соответственно;

- в свою очередь расходы бюджета вырастут на $169,7 \%$ или 25,8 трлн. юаней, с 15,2 трлн. юаней в 2014 году до показателя в 41 трлн. юаней по итогам 2023 года соответственно;

- весь исследуемый период итого бюджетной политики КНР является дефицит государственного бюджета, который к 2023 году вы- 


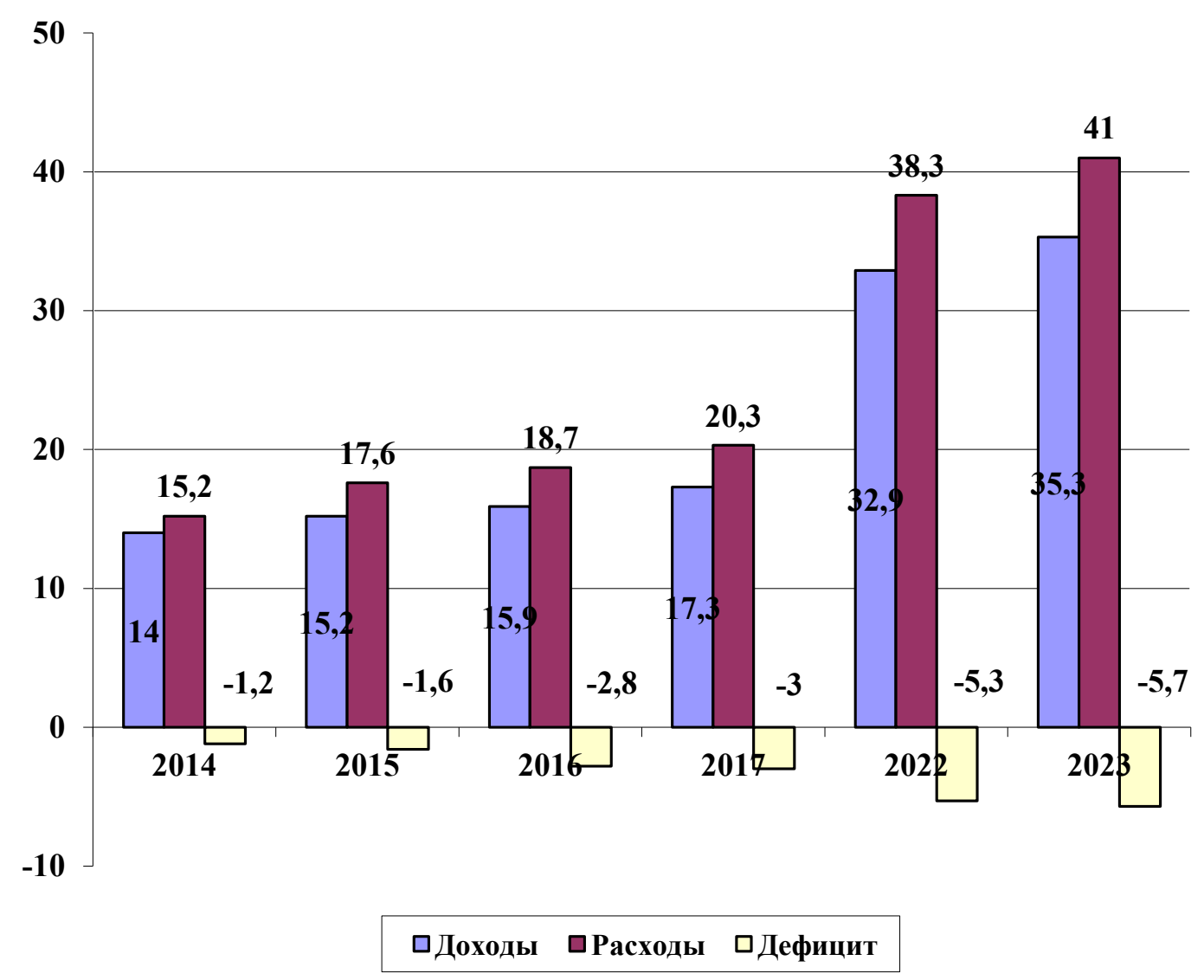

Рисунок 1 - Динамка доходов, расходов и дефицита консолидированного бюджета КНР (трлн. юаней) за 2014-2023 годы [5-9]

растет на 375\% или 4,5 трлн. юаней, с 1,2 трлн. юаней в 2014 году до 5,7 трлн. юаней по итогам 2023 года соответственно.

В рамках более, предметного восприятия темы данного научного исследования осуществим анализ структуры доходов государственного бюджета Китайской Народной Республики за период с 2014 по 2017 год соответственно.

Для чего воспользуемся нижеприведенной диаграммой (Рисунок 2), на которой наглядно отображены данные показатели за анализируемый период.

Как можно увидеть из вышеприведенной диаграммы, за анализируемый период произошли следующие изменения в структуре и динамике структурных составляющих доходной части государственного бюджета Китая:

- в целом за анализируемый временной период налоговые поступления в доходную часть бюджета КНР выросли на 21\% или 2,5 трлн. юаней, с 11,9 трлн. юаней в 2014 году до показателя 14,4 трлн. юаней по итогам 2017 года соответственно;
- в свою очередь за аналогичный временной период неналоговые поступления доходной части бюджета Китайской Народной Республики выросли на 33,3\% или 0,7 трлн. юаней, с 2,1 трлн. юаней в 2014 году до показателя в 2,8 трлн. юаней по итогам 2017 года соответственно;

- доля налоговых поступлений в общей структуре доходов бюджета Китайской Народной Республики за период исследования снизилась на 1,3 п.п., с 85\% в 2014 году до показателя 83,7\% по итогам 2017 года соответственно;

- доля неналоговых поступлений в общей структуре доходов бюджета Китайской Народной Республики за период исследования выросла на 1,3 п.п., с 15\% в 2014 году до показателя 16,3\% по итогам 2017 года соответственно.

Учитывая существенное превалирование налоговых поступлений в структуре доходов бюджета Китайской Народной Республики над неналоговыми доходами, считаем необходимым, осуществить развернутый структурный анализ налоговых поступлений государственного бюджета КНР за период с 2014 по 2017 год соответ- 


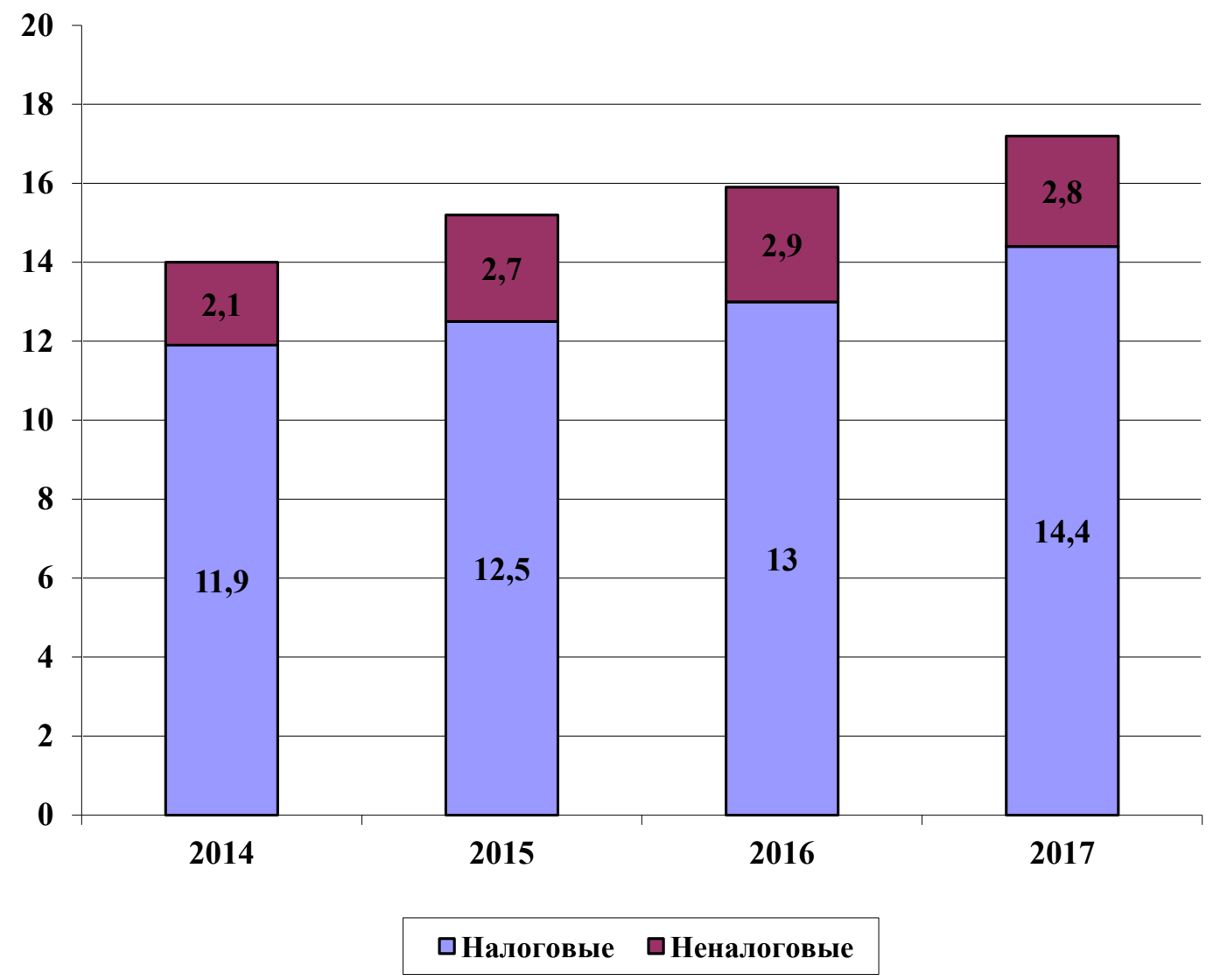

Рисунок 2 - Структура доходов государственного бюджета КНР (трлн. юаней) за 2014-2017 годы [5-9]

ственно.

Для чего воспользуемся нижеприведенной диаграммой (Рисунок 3), на которой наглядно отображены ключевые элементы структурных составляющих налоговых поступлений государственного бюджета Китая за анализируемый временной период.

Как можно увидеть из вышеприведенной диаграммы произошли следующие преобразования в системности налоговых поступлений государственного бюджета КНР:

- поступления НДС выросли на 2,5 трлн. юаней, с 3,1 трлн. юаней в 2014 году до 5,6 трлн. юаней по итогам 2017 года. Доля данного налога в доходах бюджета выросла с 26\% в 2014 году до 39\% по итогам 2017 года;

- поступления налога на прибыль корпораций выросли на 0,6 трлн. юаней, с 2,6 трлн. юаней в 2014 году до 3,2 трлн. юаней по итогам 2017 года. Доля данного налога в доходах бюджета выросла с 21\% в 2014 году до 22\% по итогам 2017 года;

- в целом можно отметить высокую централизации доходов бюджета КНР в рамках двух ключевых налогов НДС и налога на прибыль корпораций. Совокупно данные налоги формируют 51\% налоговых поступлений бюджета Китайской Народной Республики по итогам 2017 года соответственно.

Раскрывая сущность политик КНР, в бюджетной сфере проанализируем структуру расходов государственного бюджета Китая за период с 2014 по 2017 году.

Для чего воспользуемся нижеприведенной диаграммой (Рисунок 4), на которой наглядно отображены данные показатели за анализируемый временной период.

Как можно увидеть из вышеприведенной диаграммы, расходы государственного бюджета Китайской Народной Республики структурированы следующим образом по итогам 2017 года:

- на образование приходится 3 трлн. юаней или $20,8 \%$ от общего объема расходов;

- на социальную защиту приходится 2,5 трлн. юаней или $17,4 \%$ от общего объема расходов;

- на поддержку городских и сельских общин приходится 2 трлн. юаней или 13,8\% от общего 


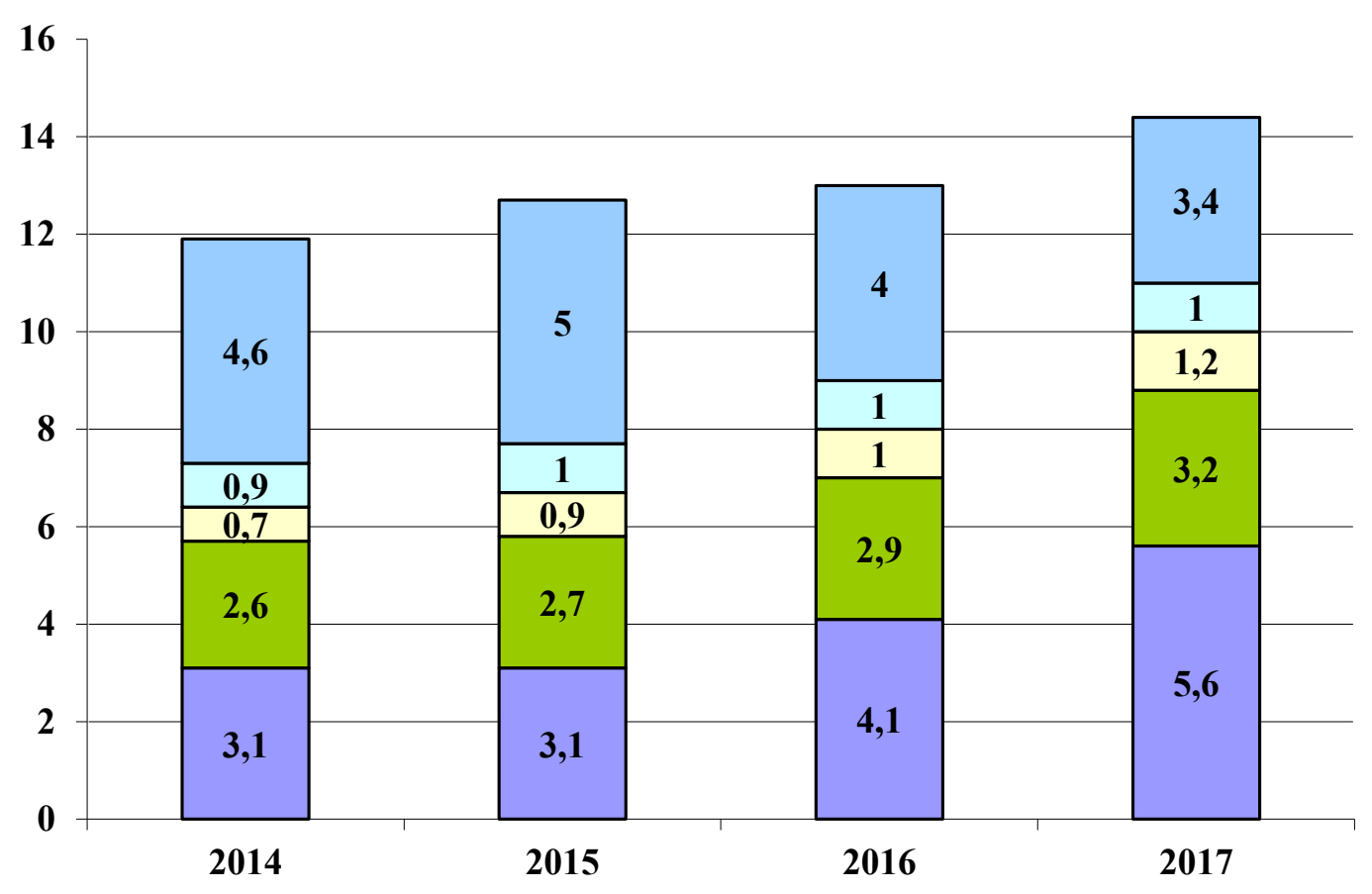

\begin{tabular}{|c|c|}
\hline 口ндС & 口Налог на прибыль корпораций \\
\hline 口Подоходный налог & 口Налог на внетрреннее потребление \\
\hline
\end{tabular}

Рисунок 3 - Структура налоговых поступлений государственного бюджета КНР (трлн. юаней) за 2014-2017 годы [5-9]

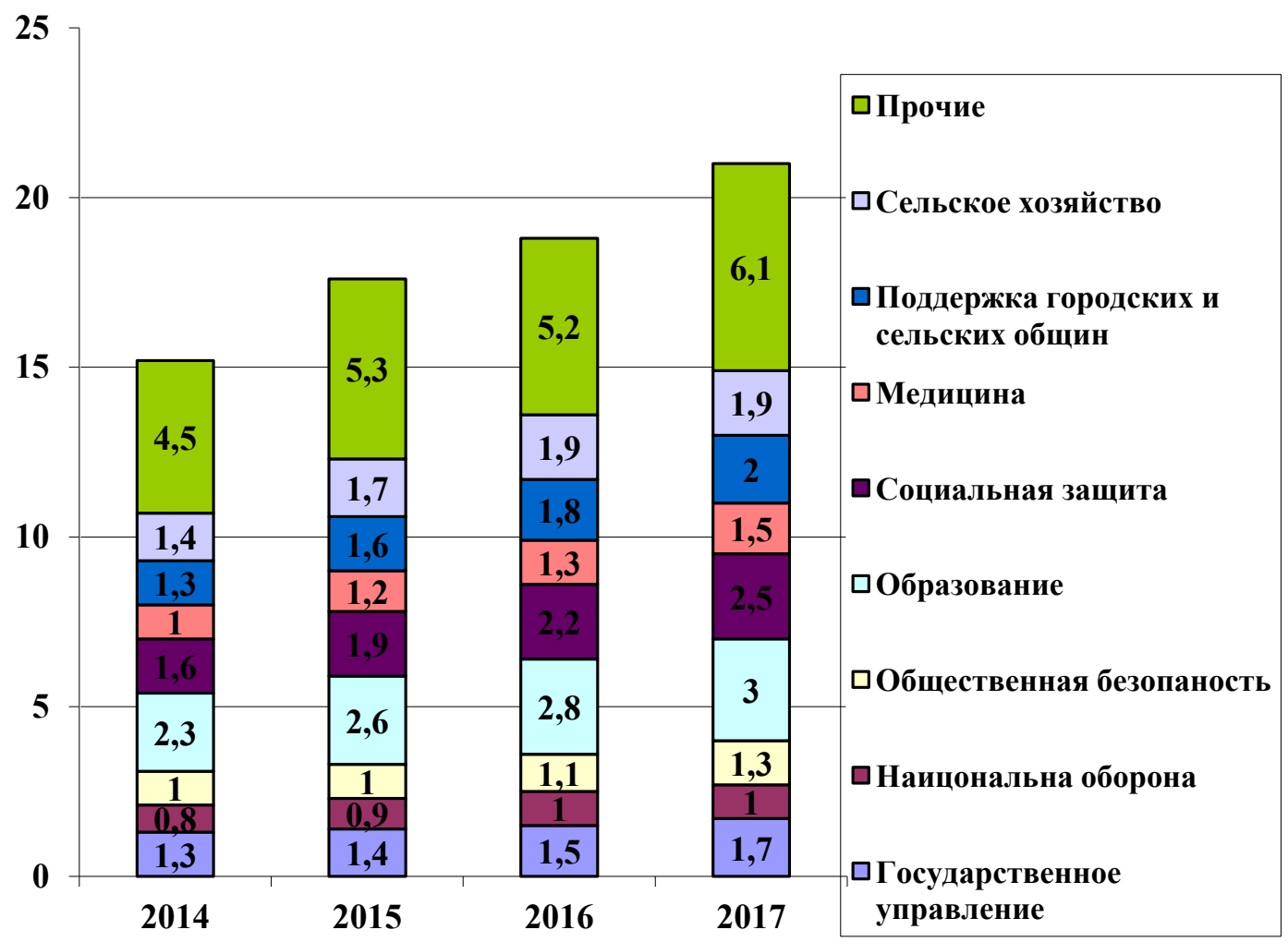

Рисунок 4 - Структура расходной части государственного бюджета КНP (трлн. юаней) за 2014-2017 годы [5-9] 
объема расходов;

- на сельское хозяйство приходится 1,9 трлн. юаней или $13,2 \%$ от общего объема расходов;

- данные статьи расходов формируют более $65 \%$ расходной части бюджета КНР.

Заключение. Как итог вышеизложенного исследования можно сделать следующие выводы:

- государственный бюджет КНР за последние четыре года и в прогнозе до 2023 года формируется и выполняется в рамках ежегодно увеличивающегося дефицита, однако учитывая внешние резервы государства, а также рост внешней торговли данный фактор не является проблематичным для финансовой системы Ки- тая;

- в структуре доходов бюджета Китайской Народной Республики преобладают налоговые поступления - более 80\% от общего объема поступлений бюджета;

- в структуре налоговых поступлений КНР преобладают два вида налогов - НДС и налог на прибыль корпораций, совокупная доля которых формирует более 50\% налоговых поступлений в бюджет страны;

- в структуре расходов бюджета преобладают расходы на образование, социальную сферу, сельское хозяйство и медицину, которые составляют более $50 \%$ расходов бюджета государства.

\section{Библиографический список}

1. Жариков М.В. Согласованная налогово-бюджетная политика стран БРИКС [Электронный ресурс] - Режим доступа: https://cyberleninka.ru/article/n/soglasovannaya-nalogovo-byudzhetnaya-politika-stran-briks (Дата обращения: 16.03.2019)

2. Зулькарнай И.У.Стимулы экономического развития, создаваемые бюджетной системой Китая для всех уровней государственного и местного управления [Электронный ресурс] - Режим доступа: https:/ cyberleninka.ru/article/n/stimuly-ekonomicheskogo-razvitiya-sozdavaemye-byudzhetnoy-sistemoy-kitayadlya-vseh-urovney-gosudarstvennogo-i-mestnogo-upravleniya (Дата обращения: 16.03.2019)

3. Кадочников Д.В.Бюджетная система Китая на современном этапе: ключевые вызовы и направления развития [Электронный ресурс] - Режим доступа: http://ecsocman.hse.ru/data/2018/10/06/1251870113/ kadochnikov.pdf (Дата обращения: 16.03.2019)

4. Кадочников Д.В.Бюджетная децентрализация и межбюджетные отношения: опыт китайских реформ и его актуальность для России [Электронный ресурс] - Режим доступа: https://cyberleninka.ru/article/n/ byudzhetnaya-detsentralizatsiya-i-mezhbyudzhetnye-otnosheniya-opyt-kitayskih-reform-i-ego-aktualnostdlya-rossii (Дата обращения: 16.03.2019)

5. China Statistical Yearbook 2015 [Электронный ресурс] - Режим доступа: http://www.stats.gov.cn/tjsj/ndsj/2015/ indexeh.htm (Дата обращения: 16.03.2019)

6. China Statistical Yearbook 2016 [Электронный ресурс] - Режим доступа: http://www.stats.gov.cn/tjsj/ndsj/2016/ indexeh.htm (Дата обращения: 16.03.2019)

7. China Statistical Yearbook 2017 [Электронный ресурс] - Режим доступа: http://www.stats.gov.cn/tjsj/ndsj/2017/ indexeh.htm (Дата обращения: 16.03.2019)

8. China Statistical Yearbook 2018 [Электронный ресурс] - Режим доступа: http://www.stats.gov.cn/tjsj/ndsj/2018/ indexeh.htm (Дата обращения: 16.03.2019)

9. Report for Selected Countries and Subjects [Электронный ресурс] - Режим доступа: https://www.imf.org/ external/pubs/ft/weo/2018/01/weodata/weorept.aspx?pr.x=34\&pr.y=6\&sy=2016\&ey=2023 \&scsm=1 \&ssd= $1 \&$ sort $=$ country \&ds $=. \& b r=1 \& c=924 \& s=N G D P D, G G R$, GGR_NGDP, GGX, GGX_NGDP, GGXCNL, GGXCNL_ NGDP\&grp=0\&a= (Дата обращения: 16.03.2019) 